\title{
Plasma electrolysis method for reducing COD in tofu wastewater
}

\author{
Widya Pangestika ${ }^{1}$, Nadira Kamilia Permatasari ${ }^{1}$, and Nelson Saksono, ${ }^{1, *}$ \\ ${ }^{1}$ The Department of Chemical Engineering, Faculty of Engineering, Universitas Indonesia, Depok 16424, Indonesia
}

\begin{abstract}
Chemical Oxygen Demand (COD) is one of pollution parameter that have to be reduced so the wastewater may not harm the environment. Tofu wastewater is one of the organic wastewater that have high concentration of COD. The level of COD in untreated tofu wastewater outnumbered $8000 \mathrm{mg} / \mathrm{L}$. This parameter could be lowered by plasma electrolysis that produced radical species to degrade pollutants in the wastewater. Three variations had been done in this study, such as: the addition of $\mathrm{Fe}^{2+}$ ion as a catalyst, the voltage, and the depth of anode. It was shown that addition of $60 \mathrm{mg} / \mathrm{L}$ of $\mathrm{Fe}^{2+}$ ion in plasma electrolysis could degrade COD in tofu wastewater to $73 \%$. The effect of the voltage also had been studied. By using the voltage at $750 \mathrm{~V}$ could discard COD as much as $85 \%$. The last variation that was conducted in this study is the effect of the depth of anode in plasma electrolysis. The result showed that $73 \%$ of COD in tofu wastewater could be reduced by using the depth of anode $2 \mathrm{~cm}$. All of these results showed that plasma electrolysis is a potential method to degrade pollution parameter, especially COD in tofu wastewater.
\end{abstract}

\section{Introduction}

Most people in Indonesia eat tofu as a daily food because of its nutrition. To meet the needs, many tofu plants were established. They would generate a lot of waste in the processes. In general, tofu waste is divided into three categories: the solid waste or so-called tofu dregs, the wastewater, and the gaseous waste that is generated from fumes cooking process and foul odor from biodegradable waste. The tofu dregs is often used as feed ingredients however, it does not apply to the liquid waste.

Tofu wastewater is usually produced by immersing, washing, clumping, and pressing processes. It contains many organic materials and make the level of chemical oxygen demand increased. If this wastewater is not treated well, it will release bad odor to the environment because of the organic materials content. COD in untreated tofu wastewater outnumbers $8000 \mathrm{mg} / \mathrm{L}$. This wastewater is classified as the hazardous waste for the environment, as a consequence, the state minister of environment in Indonesia confirmed that the quality standar of COD in tofu wastewater has to be below 300 $\mathrm{mg} / \mathrm{L}$.

Research about tofu wastewater treatment had been done before by using many different methods, such as biofilter aerobic. This method could degrade COD in tofu wastewater to $72,93 \%$ [1]. Electrochemical process was also studied to reduce the COD level, but it could only lowered the COD level in tofu wastewater as much as $42,11 \%$ [2]. The next method to decrease the COD degree was using advanced oxidation process, but it only could reduce COD as much as $15,23 \%$ [3]. All of those methods showed that the level of COD in tofu wastewater was still being over the quality standard.
Therefore in this study, we learned about another method that might increase the degradation of COD significantly. The method that we used to treat the wastewater in this study was plasma electrolysis.

Plasma electrolysis is an electrochemical process that use a high voltage to form plasma charge that is occurred among the anode and the electrolyte surface $[4,5]$. Plasma electrolysis took place after the conventional electrolysis had been occurred. It is confirmed that this electrolysis occurred with hydrogen gas formation at the cathode and oxygen gas formation at the anode [6]. This process will form energetic species, with the hydroxyl radical as the strongest one [5]. Plasma electrolysis had been studied as an effective method to treat wastewater $[7,8]$.

Two process variables that have great effect in degrading pollution parameters in wastewater are the voltage and the concentration of $\mathrm{Fe}^{2+}$ ion as the catalyst [5]. In addition, the depth of anode is also another important factor that has to be noticed in plasma electrolysis process $[9,10]$. Therefore in this paper, we would focus on the effectiveness of those three factors to reduce $\mathrm{COD}$ in tofu wastewater.

\section{Experimental Procedures}

\subsection{The apparatus of plasma electrolysis}

The plasma electrolysis reactor was a waste treatment reactor comprised of a 2 L-beaker glass and equipped with a water cooling system to keep the temperature at $50^{\circ} \mathrm{C}$. The volume of tofu wastewater processed was 1.5 L. In this study, type of cathode used was Stainless

\footnotetext{
*Corresponding author: nelsonsaksono@gmail.com
} 
Steel-316. The form of this cathode was a solid cylinder with a length of $27 \mathrm{~cm}$ and a diameter of $0.5 \mathrm{~cm}$. Tungsten (wolfram) was used as an anode, with a length of $17.5 \mathrm{~cm}$ and a diameter of $0.32 \mathrm{~cm}$. Electrical equipment utilized was multimeter, diode bridge, trafo, and slide regulator, as can be seen in Fig. 1.

Anode was enclosed by a glass sheath equipped with an air injector, so it could be used as a medium to inject air into the working solution. The flow rate of the air that was injected into the solution was $2 \mathrm{~L} / \mathrm{min}$. If the depth of the anode used was $2 \mathrm{~cm}$, then the magnitude of the variation was measured from the bottom of the glass sheath to the surface of the solution. Every variation of the anode depth, the length of the anode contacted directly with the waste is $0.5 \mathrm{~cm}$. The illustration of anode could be seen in Fig. 1. reactor. The anode was conditioned to be submerged as deep as $20 \mathrm{~mm}$ from the surface boundary. The flow rate of the air injector was set at $2 \mathrm{~L} / \mathrm{min}$. Then, the electricity was turned on and the regulator voltage was set starting from $22.7 \mathrm{~V}$. The voltage was increased until the plasma occurred. The phenomenon that happened in plasma electrolysis reactor was documented well. Every part of the apparatus of the setup had to be well observed and confirmed in a good condition. The voltage kept to be increased, then it was left momentarily at that point until the current and voltage were stable, and the current was recorded. After that, the voltage was increased slowly until it reached $750 \mathrm{~V}$. If the measured current were fluctuated, the current values were recorded longer, then they were averaged. This process was carried out at a constant temperature, $50^{\circ} \mathrm{C}$.

\subsection{Testing the performance of plasma electrolyis experimental setup}

As much as $1.5 \mathrm{~L}$ of tofu wastewater and $0.02 \mathrm{M} \mathrm{Na}_{2} \mathrm{SO}_{4}$ were added into the plasma electrolysis reactor. Iron catalyst, $40 \mathrm{mg} / \mathrm{L} \mathrm{FeSO} \cdot 7 \mathrm{H}_{2} \mathrm{O}$, was mixed into the

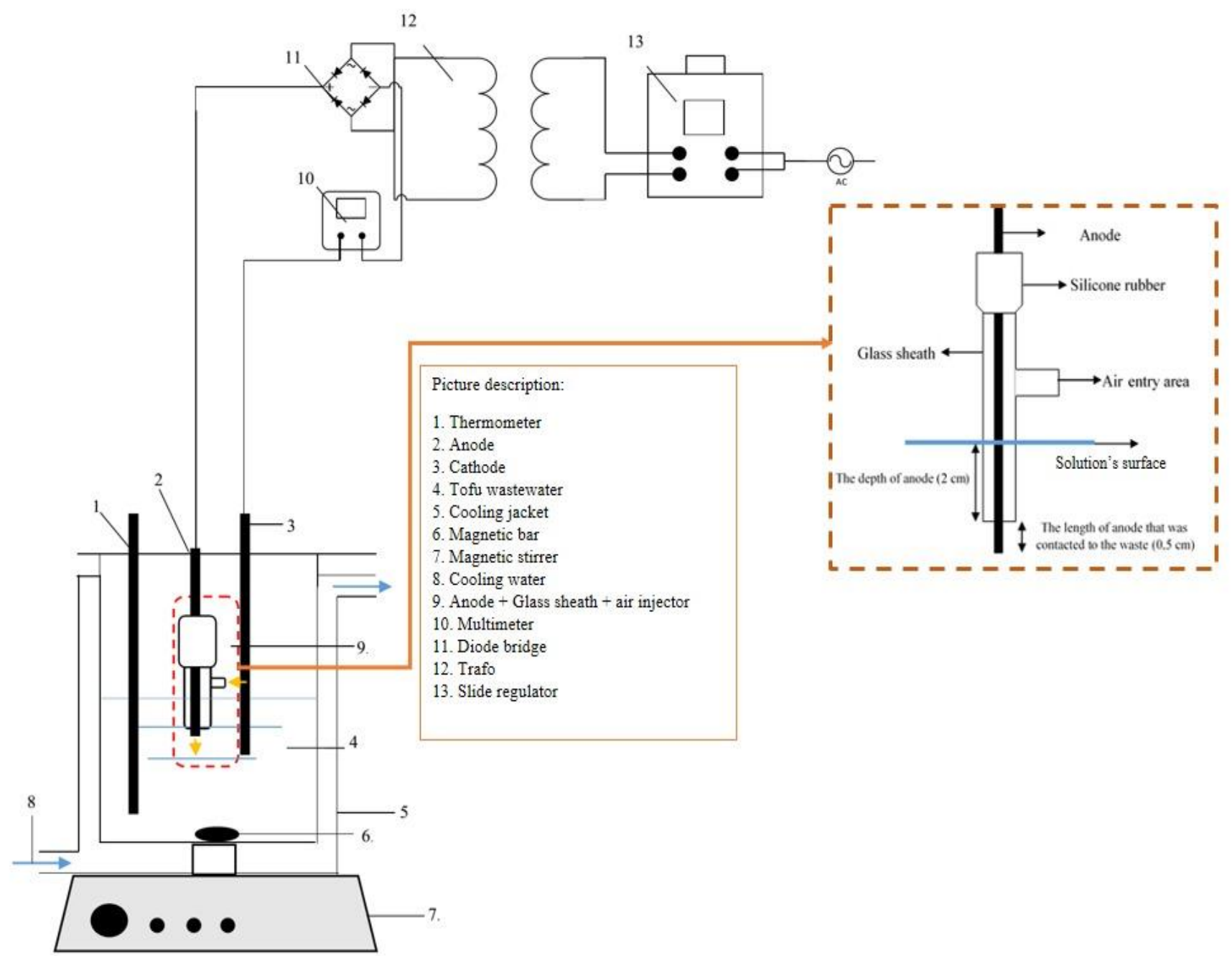

Figure 1. The schematic diagram of experimental setup for plasma electrolysis 


\subsection{COD degradation of tofu wastewater}

There are 3 variation that was studied in this experiment, such as: the addition of $\mathrm{Fe}^{2+}$ ion as a catalyst, the voltage, and the depth of anode. For the addition of $\mathrm{Fe}^{2+}$ ion variation, we used $700 \mathrm{~V}$ and immersed the anode 2 $\mathrm{cm}$ from the surface. For other variation, such as the voltage, we added $60 \mathrm{mg} / \mathrm{L} \mathrm{Fe}^{2+}$ ion as the catalyst into the working solution and immersed the anode $2 \mathrm{~cm}$. For the last variation, we set the voltage to $700 \mathrm{~V}$ and added $60 \mathrm{mg} / \mathrm{L} \mathrm{Fe}^{2+}$ ion as the catalyst into the working solution.

Before the treatment, the tofu wastewater was filtered by using filter cloth. The COD of this filtered wastewater was measured according to method in SNI 6989-2-2009. Then, the solution and $0.02 \mathrm{M} \mathrm{Na}_{2} \mathrm{SO}_{4}$ are fed into the plasma electrolysis reactor. Iron catalyst was added and mixed into the reactor. The anode was conditioned to be submerged as deep as $2 \mathrm{~cm}$ from the surface boundary, except for the the depth of anode variation. The voltage regulator was switched on and the voltage raised slowly. The process of plasma electrolysis was carried out for $10,20,30,40,60,90$, and 120 minutes. After its variation of time, the waste sample was taken and its COD content were measured.

\section{Results and Discussion}

In this research, we used $\mathrm{Na}_{2} \mathrm{SO}_{4}$ as the electrolyte. This solution was chosen because the amount of hydrogen peroxide produced in that solution are greater than other electrolytes [11]. The distance of the cathode and the anode was set at $4 \mathrm{~cm}$. If the distance between the anode and the cathode was less than $1 \mathrm{~cm}$, then the anode would be crushed or eroded [12]. Another condition process of plasma electrolysis in this research was the presence of air injection in the anode, with the flow rate at $2 \mathrm{~L} / \mathrm{min}$. The air entered the working solution would help to produce more radical species that could attack more organic contaminants [13, 14], made the plasma became more stable, and decreased the consumption energy.

\subsection{The effect of the voltage on the percentage of COD degradation of tofu wastewater}

The bigger te voltage, the greater the amount of hydroxyl radicals that will be produced $[5,10]$. Hydroxyl radicals are so reactive to degrade material organic in tofu wastewater [15]. Those species would make the percentage of COD degradation of tofu wastewater increased as long as the voltage went up. From Fig. 2, we know that the highest COD degradation appeared when using $750 \mathrm{~V}$, followed by $700 \mathrm{~V}$ and $650 \mathrm{~V}$. From the graph we can see $600 \mathrm{~V}$ as the voltage that resulted the least COD degradation.

The rate of COD degradation in every used voltage were different. At $750 \mathrm{~V}, \mathrm{COD}$ degradation peaked at 40 minutes and the graph showed a slight increase after that time. While using $650 \mathrm{~V}$, the rate went up extremely for a longer time, and there was no a significant rising when using $600 \mathrm{~V}$. These datas represented the relation of those variables, that the higher the voltage, the bigger the rate of COD degradation occurred.

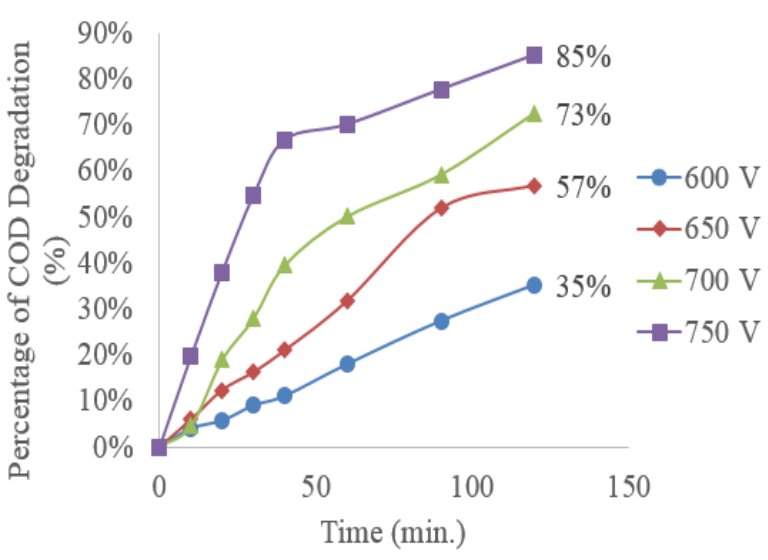

Figure 2. The relation of COD degradation to the time of plasma electrolysis on the voltage variation

On the other side, there were some losses if the voltage used was too high. The first disadvantage was the anode that was being used became eroded faster and the subsequent loss was the energy consumed became greater.

\subsection{The effect of the depth of anode on the percentage of COD degradation of tofu wastewater}

The line graphs in Fig. 3 illustrates the relation of the variation of the depth of anode to the percentage of COD degradation in tofu wastewater. These charts have upward trend but they are more fluctuative than the previous one, The reduction of COD in tofu wastewater tended to rise along with the deeper the anode that immersed in the solution, but it decreased while using the depth of anode at $4 \mathrm{~cm}$.

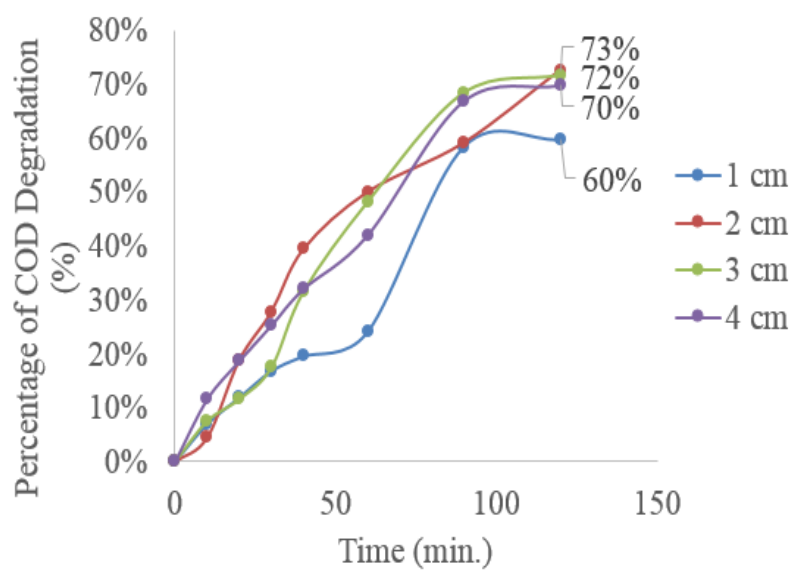

Figure 3. The relation of COD degradation to the time of plasma electrolysis on the depth of anode variation

The deeper the anode, the bigger the effect of hydrostatic pressure. It made the gas sheath around the

\footnotetext{
* Corresponding author: nelsonsaksono@gmail.com
} 
plasma became unstable and tend to move upward [9]. Therefore, the COD degradation at $4 \mathrm{~cm}$ is lower than 3 $\mathrm{cm}$. This reduction might appeared because the time for water vapor molecules for being around the plasma became shorter so they did not have enough chance to produce more hydroxyl radicals (according to the reaction 1) [5], so the amount of hydroxyl radicals in the solution would decline.

$$
\mathrm{H}_{2} \mathrm{O}(\mathrm{g}) \rightarrow \mathrm{H}^{\star}+\mathrm{OH}^{*}
$$

\subsection{The effect of the concentration of $\mathrm{Fe}^{2+}$ ion on the percentage of COD degradation of tofu wastewater}

The line graphs in Fig. 4 show an upward trend of the effect of concentration of $\mathrm{Fe}^{2+}$ ion on the percentage of COD degradation along with the time process. The hydroxyl radicals are so reactive, apart from attacking contaminants in the wastewater, it also recombined to their species very fast [16]. The recombination of hydroxyl radicals produced hydrogen peroxide. The ferrous ion increased the decomposition of hydrogen peroxyde to form more hydroxyl radicals [15]. It made ferrous sulfate that added into the solution as a great catalyst for plasma electrolysis.

With regards to the amount of COD degradation while using $100 \mathrm{mg} / \mathrm{L}$ ferrous iron, it had the highest COD degradation, on the other side, the lowest COD degradation appeared when adding no ferrous ion into the solution. There was not much difference by adding $100 \mathrm{mg} / \mathrm{L}$ and $60 \mathrm{mg} / \mathrm{L}$ ferrous ion because of the excess ferrous ion in the solution. By adding too much ferrous ion, there would be no significant degradation of pollution parameters in the wastewater $[15,17]$. The excess ion would consume the other hydroxyl radicals to form $\mathrm{Fe}^{3+}$ ion and $\mathrm{OH}^{-}$ion, then those ions would combined and made $\mathrm{Fe}(\mathrm{OH})_{3}$ in solid form [17].

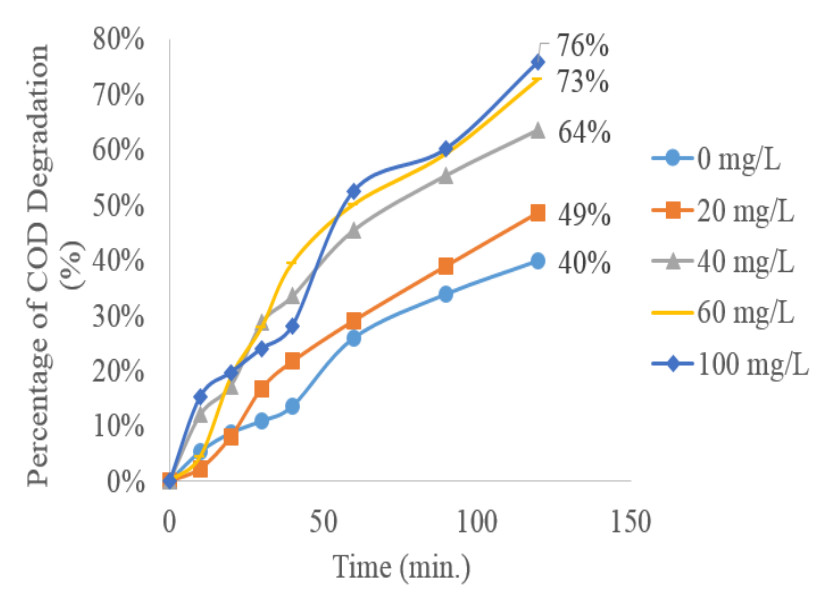

Figure 4. The relation of COD degradation to the time of plasma electrolysis on the concentration of $\mathrm{Fe}^{2+}$ ion variation

The ferrous sulfate was not only functioning as a catalyst in plasma electrolysis, but also served as a coagulant which could bind the organic substrates through sweeping floc mechanism in tofu wastewater to finally settled down, in accordance with reaction 2 below [18],

$$
\begin{aligned}
& 2 \mathrm{FeSO}_{4} \cdot 7 \mathrm{H}_{2} \mathrm{O}+\mathrm{O}_{2}+4 \mathrm{H}_{2} \mathrm{O} \rightarrow \\
& 2 \mathrm{Fe}(\mathrm{OH})_{3(\mathrm{~s})}+2 \mathrm{H}^{+}+2 \mathrm{SO}_{4}{ }^{2-}+14 \mathrm{H}_{2} \mathrm{O}
\end{aligned}
$$

\section{Conclusion}

This research proved that plasma electrolysis was a potential method to reduce COD in tofu wastewater. Three process variables that had big impact to the plasma electrolysis process were the voltage, the concentration of $\mathrm{Fe}^{2+}$ ion, and the depth of anode. The bigger the voltage, the percentage of COD degradation in the tofu wastewater would become greater, but this relation did not apply for the variation of the depth of the anode and the concentration of $\mathrm{Fe}^{2+}$ ion that added into the solution. The best condition to reduce COD in tofu wastewater was the voltage variation at $750 \mathrm{~V}$, with the reduction as much as $85 \%$.

This research was partially funded by "Hibah Publikasi Internasional Terindeks Tugas Akhir Mahasiswa Universitas Indonesia 2018, contract no. 2499/UN2.R3.1/HKP.05.00/2018” from Directorate Research and Community Service Universitas Indonesia. The authors declare no competing interests or any conflicts of financial interests.

\section{References}

1. N. Pohan. Pengolahan Limbah Cair Industri Tahu dengan Proses Biofilter Aerobik (2008)

2. M.I Hudha, Jimmy, Muyassaroh. Prosiding Seminar Nasional Kimia, 185-191 (2014)

3. S. Zunuraen. Pengolahan Limbah Cair Industri Tahu dengan Proses Oksidasi Lanjut (AOPS) Berbasis Perokson $\left(\mathrm{H}_{2} \mathrm{O}_{2} / \mathrm{O}_{3}\right)$ (2016)

4. S.K. Sengupta, O.P. Singh. J. Electroanal. Chem.. 301, 189-197 (1990)

5. G. Jinzhang, W. Aixiang., F. Yan, W. Jianlin, M. Dongping., G. Xiao, L. Yan, Y. Wu. Plasma Sci. Tech. 10, 30-38 (2008)

6. N. Saksono, B. Ariawan, S. Bismo. IJTech 3, 8-15 (2012)

7. Y. Liu, D. Wang, B. Sun, X. Zhu. J. Hazard. Mater. 181, 1010-1015 (2010)

8. N. Saksono, B.P. Adiwidodo, E.F. Karamah, S. Kartohardjono. J. Environ. Sci. Technol. 6, 41-49 (2013)

9. S. Bismo, K. Irawan, E.F. Karamah, N. Saksono. J. Chem. Chem. Eng. 7, 6-12 (2013)

10. N. Saksono, I. Nugraha, M. Gozan, S. Bismo. Int. J. Arts Sci. 7, 71-77 (2014)

11. X.L. Jin, X.Y. Wang, H.M. Zhang, Q. Xia, D.B. Wei, J.J. Yue. Plasma Chem. Plasma Process. 30, 429-436 (2010) 
12. J. Gao, J. Yu, Q. Lu, X. He, W. Yang, Y. Li, L. Pu, Z. Yang. Dyes Pigm. 76, p. 47-52 (2008)

13. K. Yasuoka, K. Sato. Development of Repetitive Pulsed Plasmas in Bubbles for Water Treatment. (2009).

14. P.R. Gogate, A. Pandit. Adv. Environ. Res. 8, 501551 (2004)

15. G. Jinzhang, G. Xiao, M. Dongping, Y. Wu. Plasma Sci. Tech. 9, 431-435 (2007)

16. J. Gao, J. Yu, Q. Lu, W. Yang, Y. Li, L. Pu. Pak. J. Bio. Sci. 7, 1715-1720 (2004)

17. X. Jin, H. Bai, F. Wang, X. Wang, X. Wang, H. Ren. IEEE T. Plasma Sci. 39, 1099-1103 (2011)

18. A.E. Ghaly, A. Snow, B.E. Faber. Can. Biosyst. Eng. 48, 13-22 (2006) 